\title{
LA FIGURA DEL LLUNK'UY EL CLIENTELISMO EN LA BOLIVIA DE EVO MORALES
}

\section{The Ilunk'u figure and clientelism in Evo Morales'Bolivia}

\section{GAYA MAKARAN*}

Fecha de recepción: 4 noviembre de 2015 - Fecha de aprobación: 28 de enero de 2016

\section{Resumen}

El artículo pretende examinar el fenómeno del clientelismo en los gobiernos del Movimiento al Socialismo (MAS) en la Bolivia actual (2006-2015), como una herramienta de cooptación y neutralización de los movimientos sociales. Se analizará el contexto socio-histórico del fenómeno clientelista en Bolivia, tomando en cuenta las determinaciones culturales. Por lo cual el clientelismo boliviano se inscribirá en el concepto local del "Ilunk'u' o "llunkerío", relacionado con el mundo aymara-quechua. Se mostrarán los mecanismos estructurales del poder político en Bolivia que llevan al clientelismo y paternalismo estatal y sus consecuencias para la autonomía de los movimientos sociales y la calidad de la vida política del país.

Palabras clave: Bolivia, MAS, Ilunk'u, clientelismo, movimientos sociales.

\section{Abstract}

This article aims to examine the phenomenon of clientelism governments of the Movement Toward Socialism (MAS) in the current Bolivia (2006-2015), as a tool of cooptation and neutralization of social movements. The socio-historical context of the clientelism phenomenon in Bolivia will be analyzed, taking into account cultural determinations. Therefore the Bolivian clientelism shall be entered in the local concept of "llunk'u" or "llunkerío" related to the Aymara - Quechua world. Structural mechanisms of political power in Bolivia leading to clientelism and state paternalism and its consequences for the autonomy of the social movements and the quality of political life are displayed.

Keywords: Bolivia, MAS, Ilunk'u, clientelism, social movements.

\footnotetext{
* Doctora en Humanidades, Universidad de Varsovia. Investigadora del Centro de Investigaciones sobre América Latina y el Caribe (CIALC) de la Universidad Nacional Autónoma de México (UNAM). Correo-e: makarangaya@gmail.com
} 


\section{Introducción ${ }^{1}$}

En el presente artículo examinaremos el fenómeno del clientelismo en los gobiernos del Movimiento al Socialismo (MAS) en la Bolivia actual (2006-2015), como una herramienta de cooptación y neutralización de los movimientos sociales. Nuestra investigación partirá de la pregunta por la actual cultura política boliviana en los "tiempos de cambio" que, según las declaraciones oficialistas, ha experimentado un vuelco plurinacionalista y descolonizador. Nuestro objetivo es contrastar estas aseveraciones optimistas con la realidad vivida por los sectores indígena-populares y para ello revisaremos los testimonios de los actores implicados, el discurso gubernamental y los hechos relatados por los principales medios informativos del país. Dada la actualidad del tema, en esta tarea nos basaremos sobre todo en la prensa escrita boliviana.

Partimos de la hipótesis de que, lejos de un cambio sustancial, la política boliviana en los tiempos de Evo Morales se caracteriza por la perpetuación e incluso fomento de los vicios de las épocas anteriores, entre ellos el clientelismo, fenómeno de larga data que deriva de la estructura misma del régimen político boliviano. A fin de entender el actual clientelismo político, analizaremos su contexto socio-histórico, tomando en cuenta las determinaciones culturales propias. Para tal objetivo, revisaremos primeramente acercamientos teóricos al clientelismo latinoamericano como tal, para luego ahondar en la realidad boliviana a partir de conceptos de la servidumbre voluntaria y la cultura señorial en el contexto del colonialismo interno. Sin embargo, para nosotros términos clave para la interpretación del clientelismo boliviano serán el "llunk'u" junto con el "llunkerío", relacionados con el mundo aymara-quechua.
Rastrearemos sus significados y usos sociales cotidianos tanto en los discursos como en las acciones políticas, a través de las huellas dejadas en la prensa nacional.

Finalmente, una vez delineado el trasfondo histórico y social del fenómeno, además de sus implicaciones teóricas, pasaremos al análisis de las prácticas clientelistas efectuadas tanto desde arriba por el gobierno de Evo Morales, como desde abajo por las organizaciones sociales. Al mismo tiempo, indagaremos los limitantes de dichas prácticas, al subrayar los momentos recientes de rebeldía e insumisión de los sectores subalternos.

\section{Acercamiento teórico al clientelismo latinoamericano}

El clientelismo, junto con el paternalismo, tiene una larga y nutrida tradición en Bolivia, igual que en toda América Latina. Se puede decir que forma parte del habitus de amplias capas de la población boliviana, hasta el punto de llegar a incrustarse en la política como su parte integral. Definido como relaciones sociales y políticas jerárquicas de sociedades de corte patrimonialista, según el modelo de patrón-cliente (este puede ser individual o colectivo), construidas a partir de un intercambio desigual de favores de orden material y simbólico (Peralta, 2006), el clientelismo constituye una respuesta sui generis de las sociedades señoriales de legado colonial ante la modernización democrática. Es una apuesta de las elites ante la demanda incipiente de las masas de ser incorporadas a la vida política moderna, al permitirles el acceso controlado y subordinado, en la mayoría de las veces reducido a puro voto, con la simultánea conservación de las desigualdades socioeconómicas y de su monopolio político. 
Aunque el clientelismo no se limita solo a las clases bajas, son estas las que se mencionan con frecuencia como destinatarias de las políticas clientelistas, lo que se puede explicar por la precariedad material y la exclusión política que padecen. Ante esa difícil realidad se ven obligadas a recurrir a las relaciones clientelares para asegurarse su sobrevivir diario. Así, para las clases populares las redes clientelares son a veces la única posibilidad para acceder a bienes y servicios, y su aprovechamiento forma parte de una estrategia necesaria de subsistencia (Peralta, 2006).

Para las clases gobernantes, el clientelismo es útil para politizar e incorporar a las masas a la política moderna, siempre manteniendo su posición subordinada. Esta subordinación legitima al poder político y colabora en la profesionalización de la política y en la sucesiva desideologización de los partidos. De esta manera, la política deja de constituir una actividad masiva, social y horizontal, se profesionaliza, verticaliza y, finalmente, queda atrapada por una élite supuestamente capacitada para lo político. La sociedad no participa de manera autónoma en asuntos de interés público, sino que se subordina a una clase de mediadores y representantes profesionales, los políticos. Esta desciudadanización favorece el clientelismo, puesto que lo que debería ser un derecho del ciudadano se convierte en un favor, cedido desde el poder, por el cual hay que estar agradecido. De ahí el clientelismo es el reflejo de una relación de poder vertical, es un sutil mecanismo de dominación (Torres, 2007).

El clientelismo a menudo se justifica subrayando su papel redistributivo de la riqueza, sin embargo, se trataría de un goteo muy escaso de bienes y servicios a cambio de sumisión y docili- dad, que se emplea para poder continuar con la acumulación capitalista. La redistribución, a veces incluso generosa, está condicionada desde el poder y por eso siempre es selectiva y arbitraria. En la mayoría de los casos se trata de políticas de asistencia social de carácter residual que no solucionan problemas estructurales en empleo, salud, educación, puesto que son puntuales, paliativas y provisorias. Suponen un gran desembolso de los fondos públicos para los fines clientelistas privados de los líderes o partidos políticos: lo que debería ser un derecho financiado por el Estado se convierte en un don arbitrario y personal. De esta manera, se privatizan los bienes públicos para construir el capital político de las fuerzas particulares (Torres, 2007). Esto nos lleva a vincular la dimensión de las políticas clientelistas con la capacidad del presupuesto estatal: mientras más fondos se encuentren disponibles, más peso tendrá el fenómeno clientelista.

El clientelismo, aunque muchas veces asociado a un simple intercambio explícito y chantajista de favores por votos, no tiene por qué reducirse a las formas "gruesas" de cooptación, sino que puede comprender significados y emociones que complejizan la relación patróncliente al implicar la amistad, la familiaridad, la gratitud, la lealtad y la reciprocidad (formas finas). De hecho, se sabe muy bien que los lazos de cariño y afecto son mucho más eficaces que la relación clientelar directa. De esta manera, el clientelismo latinoamericano deriva de las lógicas basadas en las relaciones primarias, personales, comunitaristas, parroquiales, de compadrazgo o parentesco (premodernas), que nacieron como una respuesta a la ineficiencia o el abuso estatal como sistemas horizontales o semihorizontales de apoyo informal. Se diferencia de ellas, sin embargo, por ser siempre vertical y ejercido desde el poder dominante (Op.cit.). 


\section{Clientelismo boliviano y el Ilunk'u. Contexto socio-histórico}

El clientelismo político en Bolivia, aunque ya se puede notar en el gobierno indigenista de Gualberto Villarroel (1943-1946), inicia plenamente tras la Revolución Nacional de 1952 con el partido Movimiento Nacionalista Revolucionario (MNR) de Víctor Paz Estenssoro, que moderniza parcialmente la vida política del país con el voto universal y la sindicalización. Tiene sus claros antecedentes por una parte en las relaciones señoriales, paternalistas típicas de sociedades coloniales y colonizadas, y por la otra, en la cultura misma de la población originaria andina. Podemos destacar una fuerte jerarquización de la vida social boliviana desde los primeros años de la Colonia, basada en la categoría racial/ étnica, donde "los indios" fueron condenados a la explotación y la servidumbre, primero por los españoles y luego los criollos-mestizos. Las figuras del patrón y del cacique (kuraka), intermediario entre el mundo de los indios y los blancos, se establecieron como referentes de las relaciones sociales verticales basadas en favores y la informalidad en vez de derechos y leyes, la realidad ilustrada por el famoso "acato pero no cumplo" colonial. El legado colonial fue asumido por la joven república boliviana que formalmente ciudadanizó al indígena, pero que lo mantenía en una completa sumisión, propia de los regímenes feudales, y lo usaba como mano de obra esclava o carne de cañón en sus conflictos internos y externos (Makaran, 2012).

Estas relaciones fueron traducidas posteriormente a la vida política democrática, donde el pueblo era usado como masa votante, "escaleras" o "pongos" políticos, según las palabras del líder aymara Felipe Quispe, el Mallku (Forrest \& Thomson, 2003). La palabra "pongo" (peón, sirviente de hacienda) es aquí significativa y nos realza simbólicamente la continuidad entre el régimen de hacienda y la política boliviana moderna. Así, el MNR puso en práctica el clientelismo político como el mecanismo de dominación sutil y de la incorporación subordinada de las masas indígenas campesinas y mineras. Para tal objetivo aprovechó a los sindicatos, al quitarles la autonomía y hacerlos dependientes del Estado, tras haber cooptado a sus dirigentes y pacificado a sus bases (corporativismo):

\begin{abstract}
“Desde la Revolución de 1952 la participación política más característica de los campesinos indígenas ha sido servir como la base del poder rural de los sucesivos líderes regionales y nacionales. Eran valorados la mayoría de las veces cuando las élites necesitaban manufacturar los bloques de voto popular. En múltiples elecciones nacionales 'runas en los camiones' (...) eran transportados de rutina del campo para votar en masa como una manera de mantener los sucesivos gobiernos populistas en el poder. Los líderes indígenas frecuentemente servían como vasallos y clientes valorables de los políticos nacionales bolivianos" (Albro, 2015: traducción de la autora del texto en inglés).
\end{abstract}

Sin embargo, la lealtad de las masas hacia el tata (padre) MNR, desbordó una relación simple: votos por beneficios, y se convirtió en una alianza afectiva duradera, incluso a pesar de las evidencias del carácter cada vez más antipopular del partido. Su expresión máxima fue la alianza militar-campesina en contra de la insurgencia minera durante la dictadura del General René Barrientos (1964-1969).

Terminadas las dictaduras militares, durante la época de la democracia neoliberal (1985-2005), el clientelismo político se reforzó como el único método de conseguir votos, dada la desideologización de los partidos y su distanciamiento de las bases. Una nueva fuerza política que supo complementar el clientelismo tradicional duro con 
el otro sutil y afectivo, fue la Conciencia de Patria (CONDEPA) de Carlos "compadre" Palenque, organización que logró ganar el apoyo multitudinario de la población chola (indígena urbana) de La Paz y El Alto en los años 80, al crear vínculos de cariño y lealtad gracias a las obras efectuadas en los barrios y el uso de códigos culturales nativos y populares como la misma institución del compadrazgo (Makaran, 2008).

La cultura clientelista derivada del paternalismo señorial nos lleva a identificar una cierta postura política que asumen los "clientes" ante sus patrones, sobre todo frente al Estado y sus funcionarios, y que el pensador boliviano Luis Tapia define, tras Etienne de la Boétie, como la "servidumbre voluntaria":

\begin{abstract}
"Los individuos acceden al ejercicio de una cuota de poder estatal a través de asumir una conducta de servidumbre voluntaria. Es el deseo de ocupar alguna posesión de autoridad, lo que conlleva cierto tipo de reconocimiento social y de poder político, lo que induce a una conducta de casi total subordinación, es decir, a la eliminación de la autonomía intelectual y moral. (...) Aquí se busca lograr el reconocimiento, que implica la subordinación de otros, a través de ser elegido por el presidente y su oligarquía en alguno de los cargos de representación en el poder legislativo, tanto nacional como departamental y municipal, o como parte del poder ejecutivo o judicial" (Tapia, 2014: 41).
\end{abstract}

Esta cultura señorial se debe a una estructura económica y cultural desigual jerarquizada. El Estado reproduce esta desigualdad en la vida política y social:

\footnotetext{
"La servidumbre voluntaria es la eliminación del principio igualitario. Induce a la organización y reproducción de desigualdad política, ya que justamente busca la subordinación de los otros, como parte de una cadena de subordinación de autoridades intermedias a la cabeza del Estado" (Op.cit.: 47).
}

Además de esta tradición señorial descrita que constituye la raíz de la cultura clientelista en Bolivia, podemos buscar sus fuentes en la cultura nativa de los Andes basada en la reciprocidad y en el don, que favorecen la ayuda mutua horizontal en los contextos comunitarios, pero que pueden ser tergiversados e instrumentalizados para justificar las relaciones clientelares e incluso corruptas. Lo que parece positivo a niveles del ayllu (comunidad andina) o del barrio popular: "hoy te ayudamos a ti, mañana tú nos ayudas a nosotros"; si se usa desde las posiciones de poder solo refuerza la cultura clientelista y propicia la permisividad ante los posibles actos de corrupción.

Así como hemos relatado la larga tradición de la cultura paternalista/clientelista en relaciones entre las élites políticas criollas-mestizas y la población boliviana, mayoritariamente indígena, han existido numerosos intentos desde el campo popular de romper con este legado: desde los levantamientos indios por el autogobierno (Túpac Katari, Zarate Willka), la lucha armada y legal por las tierras comunitarias, la creación de sindicatos independientes, hasta el surgimiento del indianismo y katarismo aymara, corrientes ideológicas y políticas rebeldes (Makaran, 2012). Fue precisamente el katarismo la fuerza que postuló la necesidad de ruptura con la práctica clientelista del MNR y el "despertar" de las masas campesinas con el objetivo de formar una fuerza política propia y autónoma (Manifiesto de Tiahuanaco de 1973). Este esfuerzo abrió el camino al empoderamiento político de las poblaciones indígenas y posibilitó el posterior ascenso de Evo Morales al poder.

La actividad aymara katarista en contra del clientelismo político practicado por los parti- 
dos criollos-mestizos ( $q$ 'aras) no se limitó solo al ambiente estrictamente político, sino que ambicionó cambiar los códigos culturales de la población indígena que posibilitaran tales prácticas (Hurtado, 1986). De ahí, a la famosa triada andina: ama sua, ama llulla, ama quella (no seas ladrón, no seas mentiroso, no seas flojo) que refleja el código moral confesado por los pueblos andinos, se añadió el cuarto componente que tenía como objetivo redirigir a los demás para evitar su instrumentalización a favor del patrón: el ama llunk'u (no seas servil/ sumiso). Así el llunk'u surge como término para describir todo el complejo entramado de relaciones clientelares, del paternalismo y del colonialismo interno.

Veamos el significado y los usos de la palabra quechua, adoptada también por la lengua aymara, Ilunk'u. Así, el Diccionario Qheshwa-Castellano, Castellano-Qheshwa del reconocido escritor boliviano Jesús Lara (1971) define el término como correspondiente al adulador y lo deriva del verbo Ilunk'uy que significa "rebañar". El diccionario indica que también puede ser sinónimo de la palabra llajwaj que es lamedor. Si revisamos otro diccionario quechua-castellano, más reciente, (Herbas Sandoval, 1998) veremos que la vinculación de la palabra llunk'u con comportamientos estigmatizados como negativos se profundiza: es el "lisonjero", el "zalamero" incluso el "lameculos". Para profundizar los significados complejos del término veamos sus usos en la vida cotidiana de los quechuas-aymaras bolivianos, apoyándonos en la etnografía de Albro (2015).

De las definiciones citadas se desprende el significado claramente negativo de la palabra que compara la postura aduladora a actos denigrantes como el de lamer las "partes sucias" de los otros. De ahí el llunk'u hace referencia a la pérdida total de integridad personal y de honor, unida a la postura deshonesta, moralmente corrupta y despreciable, rechazada por la comunidad. De hecho, la comunidad y la lealtad a su origen étnico marcan las pautas de comportamiento a sus integrantes indígenas, las pautas que son violadas por el llunk'u, traidor de su pueblo y de su gente, un ser desarraigado, egoísta e hiperindividualista que se mueve solo por intereses personales a fin de obtener un ascenso en la sociedad de los blancos relacionado con una cuota de poder o de dinero. De esta manera, el llunk'u se inscribe en una larga historia de relaciones desiguales entre la población indígena y los patrones blanco-mestizos, donde los "traidores de la raza" servían de capataces del amo y esclavizaban a su propia gente (Véase el encastado de Manuel González Prada; González Prada, 1908).

Los Ilunk'us son entonces seres humanos que eligen el ascenso personal por encima de los valores comunitarios, se mimetizan con la cultura del amo y entran en su mundo, ascendiendo socialmente a cambio de la coherencia interna, de la integridad y de su dignidad: “(...) Ilunk'u es sumamente vivaz, siempre busca a la gente de peso, es adulador que frecuentemente actúa indirectamente (soslaya). Eso hace una cosa clara: la postura de llunk'u describe la actitud del cliente frente al patrón" (Albro, 2015: 294) Las poblaciones rurales suelen calificar como llunk'us a los cholos, indios urbanos, por personificar estos la ruptura con el mundo propiamente indígena y por su balanceo entre las dos culturas.

Otros calificativos que se le han atribuido al personaje es su falsedad que viola el principio moral de ama llulla: "no habla de frente", "habla 
detrás de las cortinas", "dice puras pendejadas"; y la deshonestidad: "no trabaja para vivir", "vive de las promesas", que viola la otra regla andina la de ama quella (no seas flojo). De esta manera, el Ilunk'u es el transgresor del moral y del orden tradicional de las comunidades andinas. Otra palabra asociada al término es el llunkerío en referencia a las relaciones políticas clientelistas ("compadres de interés") y a la traición política (“llunk’us de doble fila") en referencia a los que cambian de partido según su conveniencia (Op.cit.).

\section{La época del MAS (2006-2015)}

La llegada del aymara y sindicalista cocalero, Juan Evo Morales Ayma, a la presidencia del país en 2006, consecuencia de la poderosa movilización del movimiento indígena-popular que, aunque tiene sus antecedentes de muy larga data, demostró su fuerza a partir del año 2000 con la famosa Guerra del Agua y posteriormente la Guerra del Gas de 2003². Supuso un cambio político, pareciera, sin precedentes y despertó esperanzas genuinas de terminar con los vicios de la democracia liberal e iniciar la época del "otro poder", del "mandar obedeciendo" en términos zapatistas, de una horizontalidad y rotatividad política inspirada en la cultura comunitaria, que eliminaría de una vez por todas el clientelismo y el paternalismo propios de una cultura política vertical de subordinación y de negación de la autonomía de sujetos colectivos. El partido del gobierno, Movimiento al Socialismo (MAS), asumió el rol de representante de los movimientos sociales. Los individuos indígenas, muchos de ellos vinculados con organizaciones sociales, penetraron la, hasta hace poco, impenetrable burocracia estatal, se convirtieron en ministros o ejecutores de programas y proyectos, todo esto en pos de la descolonización del Estado que, efectivamente, se institucionalizó con la nueva Constitución del Estado Plurinacional en febrero de 2009.

Sin embargo, pronto se hizo evidente que la tradición política republicana se impuso sobre las experiencias democráticas alternativas, y el clientelismo, no solo no fue eliminado sino todavía reforzado, se convirtió en la base de la construcción de coaliciones y apoyos políticos del MAS. La tendencia de seguir el camino de viejos vicios de la democracia representativa y de abandonar la senda del "otro poder" se hizo plasmable todavía en el primer año de los nuevos gobiernos cuando el MAS monopolizó la representación indígena-popular en la Asamblea Constituyente, cuando se dio la continuidad al régimen presidencial republicano y al sistema electoral liberal, cuando Evo Morales apostó por centralizar el poder decisivo reduciendo el deliberativo y perpetuándose en la presidencia, cuando se desconoció la legitimidad de la protesta de las organizaciones indígenas (El caso de TIPNIS $^{3}$ ) con una clara preferencia por la incorporación subordinada de las fuerzas sociales a través de la cooptación y la criminalización (método de la zanahoria y el palo), etc. (Tapia, 2011).

No podemos presentar con detalles todas estas políticas del "gobierno de cambio" por las limitaciones espaciales del artículo, nos concentraremos entonces en el fenómeno del clientelismo (enfoque desde arriba: patrón hacia clientes) y del llunkerío (enfoque desde abajo: clientes frente al patrón). Como subraya Luis Tapia, la cultura señorial y la relacionada con ella, la "servidumbre voluntaria", perviven en los tiempos de Evo e incluso alcanzan mayores niveles que en los años anteriores a su gobierno (Tapia, 2014). Es así debido al mayor excedente produ- 
cido por los hidrocarburos "nacionalizados"4 y el alza de precios mundiales de commodities (actualmente en baja), lo que le ha permitido al gobierno "financiar una extensa red clientelar y prebendal con la que articula su base electoral" (Op.cit.: 32). La bonanza económica que ha estado viviendo Bolivia en la presidencia de Evo Morales propicia las prácticas clientelares y el uso discrecional de recursos por el gobierno, al convertirse éste en distribuidor de bienes y servicios a las poblaciones necesitadas, lo que refuerza el sistema de prebendas necesario para mantenerse en el poder y conservar los elevados apoyos electorales. Como asegura el director del Centro Boliviano de Estudios Multidisciplinarios (CEBEM), José Blanes: "La disponibilidad de recursos para obras públicas y para distribuir bonos o beneficios entre los sectores corporativos le permitió a Morales gozar de una amplia popularidad y esquivar de esa forma un eventual desgaste" (Ordoqui, 2014).

Este clientelismo puede tener dos facetas: una individual de cooptar a los líderes sociales o intelectuales disque "orgánicos" a cambio de beneficios personales como la "pega" (puesto de trabajo), reconocimientos simbólicos y materiales (convertirse en el intelectual más citado y publicado), cuotas de poder y el acceso a las nuevas oportunidades que se abren con el mayor peso estatal en la economía (empresas estatales, contratos, proyectos, etc.); la otra colectiva-corporativista en referencia a la compra de organizaciones sociales como los sindicatos, antes autónomos, críticos y beligerantes que hoy se han convertido en fuerzas disciplinadoras del electorado a cambio de beneficios sectoriales (tierras y despenalización de la hoja de coca para los cocaleros, doble aguinaldo, influencia en el diseño legislativo, etc.). Del mismo modo, encontramos la cooptación de las poblaciones humanas no organizadas, así llamadas masas votantes, a cambio de obras, la inversión estatal selectiva, políticas sociales focalizadas (bonos y becas) y el reparto de bienes. A eso hay que añadir que el clientelismo no se limita solo a las clases populares -aunque es el que en más nos fijamos por el interés que tenemos en los pueblos y organizaciones indígenas- en realidad sus diferentes formas se aplican también a las clases medias para ganar el apoyo de los profesionistas y de la pequeña burguesía, igual que a la oligarquía, pacificada gracias al apoyo gubernamental a sus intereses a nivel legislativo (legalización del latifundio existente o de los transgénicos), a nivel de inversión regional o por la entrega de concesiones y contratos millonarios, etc.

A estas prácticas clientelistas fomentadas desde el Estado y financiadas por el extractivismo (un ejemplo de esto es el Fondo de Desarrollo Indígena Originario Campesino, FONDIOC) podemos añadir la postura de los mismos clientes llunk'us, que motivados por beneficios personales/sectoriales sacrifican su coherencia y flexibilizan sus criterios políticos. Se podrían enumerar por nombre y apellido, aunque aquí evitaremos hacerlo por la estigmatización que esto conlleva, los otrora antimasistas que hoy en día están en las filas del MAS, o los intelectuales antes críticos empedernidos del capitalismo y del extractivismo, promotores de la democracia comunitaria, que hoy en día emplean su capital académico en defensa de un gobierno que contradice claramente estos principios.

La cultura señorial, anteriormente descrita, fomenta entre los Ilunk'us el culto, desenfrenado aunque poco sincero, a la figura del presidente, que no permite ningún tipo de críticas ni disidencias y conlleva la defensa dogmática de las decisiones presidenciales o alabanzas desver- 
gonzadas a la figura del único líder /caudillo/ jefazo. Como dice en su artículo "Ama llunku" el periodista boliviano Andrés Gómez Vela:

En estos escenarios, el egoísmo y la egolatría son los ejes que ordenan las relaciones profesionales, sociales o políticas. El superior alimenta su ego y los otros se sostienen gracias al alimento que echan a ese ego que los humilla cada vez que puede para crecer más. Es una vinculación altamente dependiente y hasta enfermiza porque puede derivar en un fanatismo peligroso. (...) Realmente, son muy peligrosos porque callan lo malo, esconden el error, ocultan la verdad, no advierten el peligro y sobredimensionan lo bueno... (Gómez Vela, 2014).

Esta cultura servil y lisonjera elimina la deliberación democrática y exige la sumisión y obediencia ciega a cambio de una cuota de poder estatal. Así, el llunkerío actual sigue formando parte de una cadena de transmisión descendiente y autoritaria de las decisiones, heredada de la política criolla-mestiza, concretamente de los gobiernos tanto del nacionalismo populista como dictatoriales.

Raúl Prada Alcoreza (2010), al describir las relaciones clientelares en el gobierno de Evo Morales, subraya la importancia de las prácticas culturales indígenas, descritas por nosotros anteriormente, como la reciprocidad y la complementariedad de connotación familiar que, deformadas por la forma señorial y colonialista de la política boliviana, llevan a la privatización de relaciones comunitarias y justifican no solo el clientelismo, sino incluso la corrupción. En contraste con los gobiernos anteriores criollos-mestizos ajenos al mundo indígena, en los tiempos de Evo la frontera entre la lealtad, el apoyo a su gente y la corrupción o el nepotismo, se ha vuelto más tenue debido a la presencia en el poder de numerosos funcionarios indígenas, la cual rompe con la dicotomía clásica del patrón blanco y el cliente indio y nos introduce en el ámbito borroso de la hermandad y compadrazgo entre, pareciera, iguales.
La denuncia del llunkerío en el gobierno masista proviene tanto de las filas de la oposición indígena (katarismo, Consejo Nacional de Ayllus y Marcas de Qullasuyu, CONAMAQ, Confederación de Pueblos Indígenas de Bolivia, CIDOB) y de los intelectuales críticos, otrora cercanos al MAS, como Raúl Prada, Luis Tapia o Silvia Rivera Cusicanqui, sino que incluso surge desde las mismas entrañas del partido gobernante, al provocar la división interna en "librepensantes" y los "llunk'us", como los identifica la prensa nacional (Los Tiempos, 2013 b). Así, aunque el presidente Morales declara ser tolerante para la disidencia interna en pos de un diálogo autocrítico, en los hechos los "librepensantes" son intimidados, relegados, descalificados y hasta expulsados del partido (el caso de Rebeca Delgado o de Samuel Pamuri, véase El Diario, 2013). Basta recordar que el término mismo fue empleado por el presidente Morales con tono negativo para disciplinar a los embajadores que expresaban opiniones personales no siempre acordes con la línea del gobierno, y luego fue utilizado con el mismo tono peyorativo por el vicepresidente Álvaro García Linera para señalar a los miembros de las fuerzas oficialistas que "tuvieron el atrevimiento de expresar libremente su disconformidad con las voces de mando provenientes de las más altas cúpulas gubernamentales" (Los Tiempos, 2013b).

Es significativo este tono despectivo que usa el oficialismo cuando se refiere a la idea de pensar libremente, una actitud abiertamente rechazada y condenada por fraccionaria, reaccionaria y antirrevolucionaria. En contraste con los acusados de "librepensantes", tenemos a los "llunk'us" del gobierno, es decir: personas que "han decidido aceptar sin crítica pública alguna y en nombre de la lealtad, las directrices que les son impartidas desde los niveles jerárquicos del partido y el Gobierno" (Los Tiempos, 
2013b). Estos, aunque carguen con el desprecio de ciertos sectores de la población, gracias a su renuncia al espíritu crítico pueden contar con el apoyo y la beneplacencia del ejecutivo, cruciales en el momento de buscar un buen trabajo o desarrollar su carrera profesional.

En la prensa boliviana de los últimos años encontramos numerosas referencias a la figura del Ilunk'u masista, algunas de ellas, como la siguiente, en tono claramente burlesco pero no por eso, menos certeras:

\footnotetext{
"En días pasados me encontraba angustiado ante la crisis económica por la que atravieso y las negras perspectivas para el año que comienza, pero apareció una luz al fin del túnel vestida de chola cochabambina que me susurró en mi oreja: 'Ya no sufra, compadrituy, porque esta noche bailaremos hasta que las velas no ardan, celebrando el año de los llunkus, quienes se aprestan a ocupar altos cargos muy cerca del Tata Evo" (Los Tiempos, 2013a).
}

El texto se mofa de las relaciones existentes en el gobierno y en el partido MAS, basadas en el llunkerío, el culto al único líder, que de Hermano Evo pasó a ser el Padre (Tata) Evo, igual que del uso instrumental y esencialista de la cultura y del pensamiento indio:

"El Baile de los Llunkus había comenzado y fue organizado por la vanguardia revolucionaria de los Yatiris que - como ustedes saben- prestan servicios al canciller Choquehuanca, quien trabaja muy cerca al Padre Evo como actualmente se le llama en círculos importantes del Llunquerío" (Los Tiempos, 2013a).

Tenemos en cuenta que algunas de estas críticas y denuncias del llunkerío en la prensa nacional, provienen del sector de derecha conservadora que está disputando espacio gubernamental $y$, celoso por las cuotas de poder, tiende a ridiculizar a la nueva élite masista. Sin embargo, a nuestro parecer, el anunciante y sus intereses no cambian la certeza de lo anunciado.

Si se trata del clientelismo dirigido a los sujetos colectivos, el mecanismo obras por votos fue aplicado por el gobierno en numerosas ocasiones, sobre todo en contextos de campañas electorales o referendales, y contó con el mensaje explícito del presidente Morales o el vicepresidente García Linera: "si quieren proyectos dennos su apoyo", "si votan por la oposición no verán ninguna inversión”. Este chantaje clientelista lo vemos claramente en las palabras del "Tata Evo" en ocasión de las Elecciones de Autoridades Departamentales, Regionales y Municipales en marzo de 2015, cuando durante su visita en la ciudad de El Alto aseveró:

"Yo solo quiero decirles a nuestros abuelos, abuelas y futuras generaciones: ¿cómo yo puedo trabajar con la ciudad de El Alto con la gente de la derecha? Yo no voy a trabajar (con la derecha), hermanos. Si quieren más obras, ahí está Édgar Patana; si quieren más obras, ahí está Felipa Huanca. Hagan una reflexión, depende de ustedes" (Rivas, 2015).

En otra ocasión, esta vez en el contexto de los intentos del gabinete masista de cambiar la constitución boliviana para que le permita la reelección continua vedada por la actual Carta Magna, la reforma que tuvo que ser avalada en el referendo nacional del 21 de febrero de 2016, el vicepresidente García Linera afirmaba, aparentemente sin tomar partida ni ejercer presión, que la decisión está en las manos de la gente y que será una manera de mostrar "cuál es el cariño" que tiene por el mandatario: "Ustedes según su conciencia van a tomar su posición, pero yo pido al alcalde, a mis autoridades originarias explicar el referendo. Nos van a preguntar (en febrero), el pueblo debe decidir si 
Evo continúa o no y el pueblo decidirá cuál será su cariño, cuál será su corazón, cuál será su pensamiento, para eso es el referendo" - dijo el vicepresidente a los pobladores de Ayata, mientras entregaba las viviendas financiadas por el gobierno (Página Siete, 2015). Y luego explicitó qué tipo de relación gobierno-pueblo esperaba:

\footnotetext{
"A ese cariño, a ese apoyo que nos han dado, nosotros vamos a responder con obras, no los vamos a abandonar', dijo a exigir al alcalde del lugar a utilizar los diez millones de bolivianos de presupuesto, pues de agotar el presupuesto, el Gobierno facilitará recursos a través de proyectos del programa 'Evo Cumple, Bolivia Cambia" (Página Siete, 2015).
}

En otra ocasión, en la población Coripata, el vicepresidente seguía con su campaña a favor del Sí en el referéndum por el cambio constitucional y declaró: "Ustedes deciden quién decide que el pueblo decida, no es Evo el que decide, no es Álvaro el que decide, es el pueblo, nos van a preguntar en el referendo quién decide, si decimos el pueblo sí, si decimos que no, es el pueblo no, así va ser la cosa", mientras entregaba "una moderna infraestructura al colegio técnico humanístico ‘Juan Evo Morales`" (Página Siete, 2015). Un mecanismo parecido podemos observar durante la consulta que se llevó entre las poblaciones de TIPNIS quienes tenían que pronunciarse a favor o en contra de los planes gubernamentales de construcción de la carretera, duramente criticados por los sectores indígenas reunidos alrededor de CIDOB y CONAMAQ. EI presidente en persona visitó las comunidades en cuestión, regalando parabólicos, motores para lanchas, útiles escolares, dispensas, etc. (Véase Noticias de Indígenas, 2012).

Este sistema de prebendas y regalos mostró su cara corrupta cuando salieron a la luz las irregularidades en el Fondo de Desarrollo Indígena
Originario Campesino (FONDIOC) en inicios del año 2015. El Fondo, pensado originalmente para incentivar la inversión productiva en las comunidades indígenas y cuyos fondos provenían de 5\% del Impuesto Directo a Hidrocarburos (IDH), resultó servir a los funcionarios del MAS, indígenas o no, igual que a las Fuerzas Armadas y al gobierno en persona para financiar actos de corrupción individual y colectiva a favor del oficialismo, sin mencionar las situaciones del robo directo. Así, fueron malversadas sumas millonarias sin que ningún proyecto productivo se llevara a cabo (Véase Saavedra, 2015). El gobierno se deslindó de las irregularidades y acto seguido se encarcelaron a una serie de dirigentes indígenas y campesinos acusados de haber recibido dinero del Fondo, mientras que la ministra de Desarrollo Rural responsable de estos desembolsos, Nemesia Achacollo, aunque fue depuesta, no enfrentó ningún cargo penal.

El caso del FONDIOC merece nuestra atención, puesto que se ha convertido en el símbolo del clientelismo masista, al desnudar los mecanismos, diseñados conscientemente desde el ejecutivo, que sirvieron no solo para cooptar y corromper a varios líderes indígenas y campesinos, sino también para premiar y castigar a organizaciones y sectores enteros, igual que asegurar la perpetuación política del partido. Según las palabras de Carlos Mamani, profesor de historia y activista indígena de La Paz, citadas por Saavedra: "el Fondo estaba diseñado para favorecer la corrupción, tanto que podemos decir que éste era su verdadero fin" (Saavedra, 2016: 6).

Varios testimonios indican que los fondos del FONDIOC se empleaban en campañas electorales y referendales del MAS y, la corrupción no era 
la cuestión de excesos individuales, sino un fenómeno generalizado y fomentado por el gobierno. Así, Marco Aramayo, exdirector ejecutivo del FONDIOC, actualmente preso, reveló entregas irregulares de dinero para los presuntos "talleres" que en realidad iban destinados a la ceremonia de posesión del presidente Morales: "Yo recibí una instrucción expresa, mediante una llamada del señor Rodolfo Machaca, que había instrucción expresa del señor Presidente de entregarles los recursos del Fondo Indígena a las organizaciones sociales para llevar gente a Tiwanaku". (Op.cit.: 7) Denuncia confirmada por otro de los dirigentes que fueron parte del Directorio del FONDIOC, Joel Guarachi, quien describe el manejo indebido del dinero para la campaña política del oficialismo e identifica lo sucedido, más que como una anomalía del sistema o un episodio aislado, como una estrategia gubernamental premeditada:

\footnotetext{
"Con la moral en alto y la conciencia tranquila, queremos denunciar que esto es solo una estrategia para matar al campesino indígena originario y para matar los 500 años de resistencia y reserva moral. [...] Pero, la forma de manejo del Fondo Indígena no fue ideada por nosotros, fue ideada por el Gobierno... [...] Absolutamente, sin temor a equivocarme, el Presidente, el Vicepresidente, los ministros, han entregado en las comunidades los proyectos del Fondo Indígena, como si fuera gestión de ellos, han hecho campaña política con eso" (Erbol, 2015a).
}

Como denuncia con pruebas la periodista Amalia Pando en defensa de uno de los dirigentes implicados:

"Si a Damián Condori lo meten preso tienen que meter preso a todos los del Pacto Unidad [pacto de varias organizaciones indígena populares en apoyo al "proceso de cambio"], porque todos recibieron la misma cantidad de plata. La exministra Nemesia Achacollo les compró vehículos flamantes con recursos del Fondo Indígena para que hagan la campaña por el MAS" (Saavedra, 2016: 7).
Efectivamente, el dinero del FONDIOC se redistribuía entre las cinco organizaciones populares: la CIDOB, la Confederación Sindical de Comunidades Interculturales Originarios de Bolivia (CSCIB), la CSUTCB, la Confederación Nacional de Mujeres Campesinas Indígenas Originarias de Bolivia -"Bartolina Sisa" (CNMCIOB-"BS") y el CONAMAQ, que formaron en su tiempo el bloque de apoyo al gobierno de Evo Morales. Con el tiempo, el Fondo además de ser una herramienta de cooptación, se convirtió también en un medio muy eficaz de castigo a los insumisos, de esta manera, los sectores indígenas opositores del gobierno fueron marginados o excluidos del reparto de fondos (Véase el caso de los guaraníes de Tacovo Mora).

Podemos preguntarnos si dichas prácticas clientelistas consiguen efectivamente asegurar el apoyo incondicional de la población hacia el partido del gobierno. Los acontecimientos recientes nos muestran que su alcance resulta bastante reducido frente a la cultura política de insumisión (ama llunk'u) de las clases populares en Bolivia, como prueban las palabras del presidente de juntas vecinales de El Alto (Fejuve), Óscar Ávila quien, en reacción al chantaje electoral "obras por votos" del presidente, contestó: "El Presidente se ha equivocado, al pueblo no se le puede condicionar para que vote (...)" (Rivas, 2015). Basta decir que Evo Morales va perdiendo apoyos en lugares que anteriormente eran sus resguardos electorales: en las elecciones subnacionales de marzo de 2015 el oficialismo perdió la gobernación del departamento de La Paz y la alcaldía de las ciudades La Paz y El Alto, lugares simbólicos para el "proceso de cambio"; en el referéndum autonómico del septiembre de 2015 promovido por el MAS, el No antimasista ganó rotundamente en todos los departamentos andinos, siendo Potosí el 
que lideró el rechazo. Finalmente, tenemos la derrota del binomio Morales-García en el referéndum por la reelección de febrero de 2016 , donde se impuso el No, aunque con un escaso margen: $51.29 \%$ frente a $48.71 \%$ (OEP, 2016).

Estos hechos se vinculan con el desacredito que a nivel simbólico ha sufrido el masismo y el mismo presidente Morales visible en los gritos en contra de "los llunk'us masistas", de los mineros potosinos liderados por el Comité Cívico Potosinista (COMCIPO) que paralizaron la ciudad de La Paz el mes de julio de 2015, y la marcha de las organizaciones sociales de El Alto (CONAMAQ, Confederación Sindical Única de los Trabajadores Campesinos de Bolivia CSUTCB, Bartolinas Orgánicas, SOL.bo, etc.), los días anteriores al referendo constitucional de febrero de 2016, a favor del No y en reacción a la muerte de seis personas en el incendio provocado presuntamente por los militantes del MAS en la Alcaldía alteña, donde los movilizados:

“(...) traían consigo muñecos que representaban al presidente Morales y a sus llunku's, los cuales fueron amarrados a los vehículos. [...] Los muñecos fueron quemados, mientras el cantautor Luis Rico interpretaba Coraje en honor a los caídos en la Alcaldía de El Alto" (Página Siete Digital, 2016).

En ambos casos, el rechazo al oficialismo se expresa a través del desprecio que sienten los sujetos rebeldes por el "llunkerío" de las nuevas clases políticas.

Frente a esta creciente oleada de descontento indígena popular que inició simbólicamente todavía en el año 2010 con el rechazo de las masas alteñas al "gasolinazo" y tomó fuerza con la marcha de TIPNIS en 2011, el gobierno no solo incrementa las medidas clientelistas (la zanahoria), sino que aplica la represión y la crimina- lización de la disidencia (el palo), estas últimas visibles, por ejemplo, en la violenta represión de los indígenas marchantes por el TIPNIS en Chaparina (2011) o de los guaraníes defensores del territorio en Takovo Mora (2015). Además de la fuerza bruta ejercida contra los inconformes con las políticas de centralización antidemocrática y de la primarización económica, el gobierno de Evo Morales emplea estrategias más sutiles como la deslegitimación discursiva, la infiltración y la división de las organizaciones opositoras (el caso del CONAMAQ y de la CIDOB). De esta manera, el clientelismo oficialista está reforzado por las medidas de persuasión menos amistosas que, además de romper las resistencias tienen el objetivo de demostrar que la postura del llunk'u es la única posible y deseable. Los insumisos se arriesgan a perder no solo las prebendas y beneficios que trae consigo el nuevo poder, sino incluso sus vidas y libertades (Erbol, 2015b). Se convierten en enemigos internos, traidores a la patria y agentes del imperio, conforme un discurso reciclado de los tiempos dictatoriales de Banzer (1971-1978). De ahí, frente a la insuficiencia del clientelismo clásico de "obras por votos", el gobierno llega a emplear su versión mucho menos pacífica en tono de amenaza: "votos o garrotes".

\section{Conclusiones}

Si al definir el clientelismo, mencionamos que este se deriva de la incorporación política de grandes masas anteriormente excluidas, sin trastocar la desigualdad estructural de la sociedad, no debe sorprendernos que sea precisamente en la época de Evo Morales cuando incrementa, en vez de disminuir, el clientelismo político. En Bolivia, dada su especificidad étnica y cultural, el fenómeno clientelista se llena de significados 
propios, derivados del concepto del llunk'u, con la diferencia, comparando con los tiempos pasados, que actualmente el llunkerío se lleva en el seno de los mismos "hermanos indígenas" sin la necesidad de intervención de un patrón criollo-mestizo. Así, la llegada al poder de un representante de las clases subalternas no solo no modificó las relaciones de poder que daban vida al fenómeno clientelista, sino que las reforzó, al adoptar el nuevo gobierno posturas señoriales, autoritarias e intolerantes frente a cualquier disidencia. La democracia boliviana tradicionalmente restringida que se abrió con el desborde de las fuerzas indígenas-populares, hoy en día parece cerrarse de manera inquietante, y el ideal de "mandar obedeciendo" soñado por las bases fue, hace tiempo ya, sustituido por el "yo mando y tu obedeces" presidencialista. Existe, sin embargo, la esperanza de que el alcance del clientelismo político en Bolivia sea limitado por la tradición insumisa de las masas populares: el futuro no tan lejano mostrará si el ama llunk'u subversivo logrará imponerse sobre las tendencias autoritarias y la longeva cultura clientelista de la sociedad boliviana.-

\section{Notas}

\footnotetext{
${ }^{1}$ El artículo forma parte de la investigación titulada "Nacionalismo e identidades étnicas en la Bolivia del MAS".

${ }^{2}$ La Guerra del Agua (2000) fue una insurrección popular en Cochabamba contra la privatización del agua por la empresa Aguas de Tunari del Consorcio Bachtel durante el gobierno neoliberal del ex dictador Hugo Banzer Suárez. La Guerra del Gas (2003) fue otra de las poderosas protestas sociales, esta vez en defensa del gas boliviano y por la renuncia del presidente Gonzalo Sánchez de Lozada. Sus demandas se resumían en la nacionalización de hidrocarburos y la convocatoria a una Asamblea Constituyente. Bajo la presión del movimiento popular, el 17 de octubre de 2003 el presidente Sánchez de Lozada tuvo que abandonar su cargo y salir del país.

${ }^{3}$ TIPNIS - Territorio Indígena y Parque Nacional Isiboro-Secure, ubicado en el departamento de Beni (prov. Moxos) y Cochabamba (prov. Chapare). Debido a los planes del gobierno masista de
}

\section{Referencias bibliográficas}

Albro, R. (2015). "Indigenous Politics in Bolivia's Evo Era: Clientelism, Llunkerío, And the Problem of Stigma". Urban Anthropology and Studies of Cultural Systems and World Economic Develompent, Vol. 36, № 3. The Institute. Disponible en: http://www.jstor.org/stable/40553606 Fecha de consulta: 15 de abril de 2015.

EI Diario (2013). "Librepensantes están en la mira para ser expulsados del MAS". Disponible en: http://www.eldiario.net/ noticias/2013/2013_06/nt130617/politica.php?n=53\&-librepensantesestan-en-la-mira-para-ser-expulsados-del-mas Fecha de consulta: 17 de junio de 2013. construir una carretera transnacional a través del parque, violando su intangibilidad y los derechos territoriales y de consulta a los pueblos indígenas que lo habitan, la población en cuestión protestó al organizar una gran marcha a la sede del gobierno en La Paz (2011). La movilización fue apoyada por la CIDOB y el CONAMQ, como también por numerosos sectores sociales no indígenas. $\mathrm{EI}$ gobierno de Evo Morales respondió con descalificaciones de los marchantes, su acoso verbal y físico y su clasificación como "agentes del capitalismo verde" manipulados por las ONG.

${ }^{4}$ El decreto presidencial sobre la nacionalización de hidrocarburos del 1 de mayo de 2006, en realidad nacionalizaba el 50\% + 1 de las acciones de las empresas transnacionales, sin estatalizar ni expropiarlas. Fue una renegociación de contratos que les permitió a las empresas seguir funcionando en el suelo boliviano a cambio de pagarle al Estado boliviano mayor excedente.
Erbol (2015a). "Exmiembro del Directorio dice que se usó dinero de exFondioc en eventos". Disponible en: http://www.erbol.com.bo/ noticia/indigenas/04122015/exmiembro_del_directorio_dice_que_ se_uso_dinero_de_exfondioc_en_eventos Fecha de consulta: 4 de diciembre de 2015.

(2015b). "Denuncian persecución de indígenas en Bolivia". Disponible en: http://www.erbol.com.bo/noticia/indigenas/10122015/ denuncian_persecucion_de_indigenas_en_bolivia Fecha de consulta: 10 de diciembre de 2015.

Forrest, H. \& Thomson, S. (2003). Ya es otro tiempo el presente. La Paz: Muela del Diablo. 
Gómez Vela, A. (2014). "Ama llunk'u". Página Siete Digital. Disponible en: http://www.paginasiete.bo/opinion/2014/6/1/ Ilunku-22989.html Fecha de consulta: 13 de junio de 2014.

González Prada, M. (1908). "Nuestros indios". En Horas de Lucha. Lima.

Herbas Sandoval, Á. (1998). Diccionario de quichua a castellano. Tunturi: Qañiywa.

Hurtado, J. (1986). Katarismo. La Paz: Hisbol.

Lara, J. (1971). Diccionario qheshwa-castellano, castellanoqheshwa. Cochabamba: Amigos del Libro.

Los Tiempos (2013a). "La noche de los llunkus". Disponible en: http://www.lostiempos.com/diario/opiniones/columnistas/20130120/ la-noche-de-losllunkus_199514_425656.html Fecha de consulta: 13 de enero de 2013.

(2013 b) "Entre 'llunkus' y 'librepensantes'”. Disponible en: http://www.lostiempos.com/diario/opiniones/editorial/20130620/ entre"llunkus"-y-“librepensantes"_217511_468433.html Fecha de consulta: 20 de junio de 2013

Makaran, G. (2008). "Identidad étnica y nacional en Bolivia a finales del siglo XX". Latinoamérica. Revista de Estudios Latinoamericanos, №. 46. México: CIALC, UNAM.

(2012). Identidades confrontadas. Conflictos identitarios en Bolivia. México: CIALC.

Noticias de Indígenas (2012). "Morales lleva otra vez regalos a las comunidades del TIPNIS". Disponible en: http://indigenas.allinnin. com/2012/07/morales-Ileva-otra-vez-regalos-las.html Fecha de consulta: 5 de julio de 2012.

OEP (2016). Resultados del Referendo Constitucional 2016. La Paz: Órgano Electoral Plurinacional Bolivia. Disponible en: http:// www.oep.org.bo Fecha de consulta: 23 de febrero de 2016.

Ordoqui, A. (2014). "Cómo logra Evo Morales mantener su popularidad en Bolivia". Infobae. Disponible en: http://www.infobae. com/2014/10/09/1600719-como-logra-evo-morales-mantener-supopularidad-bolivia Fecha de consulta 9 de octubre de 2014.
Página Siete Digital (2015). "García Linera dice que el pueblo dirá cuál es su cariño en referendo para reelección de Evo". La Paz. Disponible en: http://www.paginasiete.bo/nacional/2015/9/27/garcialinera-dice-pueblo-dira-cual-carino-referendo-para-reeleccion-71519. html Fecha de consulta: 27 de septiembre de 2015.

(2016). "El No retumba en San Francisco tras una marcha desde El Alto". La Paz. Disponible en: http://www.paginasiete.bo/ nacional/2016/2/18/retumba-francisco-tras-marcha-desde-alto-87126. html Fecha de consulta: 18 de febrero de 2016.

Peralta, M. I. (2006). Las estrategias del clientelismo "social". Buenos Aires: Espacio.

Prada Alcoreza, R. (2010). “¿Hacia una gestión pública plurinacional?". En Svampa, M., Stefanoni, P. \& Fornillo, B. (eds.). Balance y perspectivas. Intelectuales en el primer gobierno de Evo Morales. La Paz: Archipiélago.

Rivas, M. (2015). "Fejuve dice que Evo se equivocó al condicionar el voto alteño”. La Razón. El Alto. Disponible en: http://www.la-razon. com/nacional/animal_electoral/Subnacionales-Fejuve-Evo-equivococondicionar-voto-alteno_0_2244975517.html Fecha de consulta: 1 de abril de 2015.

Saavedra, J. L. (2015). "Corrupción en el Fondo Indígena de Bolivia”. Pukara, año 9, № 105. La Paz.

(2016). "Fondo Indígena: corrupción y persecución política en 'tiempos de cambio”'. Pukara, año 10, № 114. La Paz.

Tapia, L. (2014). El leviatán criollo. La Paz: El Horizonte Interior. (2011). El Estado de derecho como tiranía. La Paz: CIDES, UMSA.

Torres, P. J. (2007). De políticos, punteros y clientes. Reflexiones sobre el clientelismo político. Buenos Aires: Espacio. 